\title{
Student Engagement: towards a critical policy sociology
}

\author{
Michael Tomlinson \\ University of Southampton \\ Email: m.b.tomlison@soton.ac.uk
}

This paper develops a critical policy analysis of the student engagement agenda, exploring its establishment as a key policy framework in HE and why it has developed such momentum. Based on a critical policy sociology approach, this article analyses the levels through which student engagement can be conceptualised: macro, meso and micro. At the macro level, the concept can be seen as partly aligned to the market-driven and massified institutional context and informed by New Public Management policy levers intended to enhance the performative value of contemporary universities. At the meso level, student engagement has been instituted by policies and practices evaluated by a range of performance measures that purportedly capture the efficacy of engagement practices. At a micro level, it presents issues around students' relationship with institutions in light of their changing role. If student engagement policy and practice is able to elevate students as active co-producers of self-directed learning, they may also potentially affirm their role as regulatory customers.

Policy sociology; neoliberalism; performativity; engagement; studentship

\section{Introduction: problem and context}

The concept of student engagement has become firmly established in the lexicon of contemporary higher education (HE) policy and has informed much discussion on the 
management of student experience (Kuh, 2010). However, it remains conceptually ambiguous, largely due to the multiple ways in which it can be conceived and the multiple contexts in which it is played out (Baron and Corbin, 2012). Student engagement has been defined broadly as the level of effort and investment students make towards their formal study, resulting from educationally purposeful provision that enriches their formal experiences. It is acknowledged that it is likely to have multiple components - for instance, Trowler (2010) has identified cognitive, emotional and behavioural dimensions, each of which are achieved through different facets of students' experiences. Much of the research and analysis has framed the issue in terms of the favourable institutional and pedagogic conditions that encourage students to make further cognitive investments in their higher education learning.

A key concern preoccupying those involved in HE teaching and learning has been to develop institutional and pedagogic strategies that enhance student engagement (Coates, 2005). This is followed by endeavours to best capture how effective these are and how well they can be implemented and then measured. This tends to work from the premise that student engagement provision is inherently beneficial to students and that provision must be tailored to enrich its impact. Student engagement has therefore become viewed as a key lever towards the enhancement of institutional effectiveness and quality at a time when policy makers have emphasised the importance of maximising the formal benefits of participating in HE. This has also taken place during a period when, in many countries at least, the costs of participating have transferred more significantly onto individual students. There are a reportedly large range of associated benefits from improved student engagement, ranging from enhanced subject knowledge, employability development, meta-cognitive skills acquisition and positive dispositions towards continued learning (Coates, 2005) 
An alternative focus, and one which invites a different level of analysis, is to consider why the concept of student engagement has become so pervasive in contemporary higher education. Drilling further down into this question opens up related issues concerning why HEIs across most international contexts have largely been so willing to embrace this agenda and what may be at stake in the pursuit for making students more fully engaged in their formal learning. To address such questions, the focus shifts from mainstream policy questions concerning its effective implementation and enhancement to the shifting institutional and policy context that has given rise to this agenda and helps continue its momentum.

This article engages with this agenda by drawing on some of the perspectives of critical policy sociology. In employing this approach, the paper locates student engagement across three levels: macro, meso and micro. This article illustrates how, at the macro level, the concept of student engagement can be seen as partly aligned to the market-driven and massified institutional context. The marketization of HE is underpinned by a neoliberal ideological policy framework and new public management policy levers intended to enhance the value and outputs of contemporary universities. At the meso level, student engagement is largely instituted by policies and practices evaluated by a range of performance measures that purportedly capture the efficacy of engagement practices. At a micro level, it maps onto significant issues about students' formal learning experiences and related expectations in light of their changing role. This is intimately connected to continued discussions of students' relationship with institutions and shifting identity positions in a mass marketised HE context. 


\section{Applying a policy sociology perspective}

'Policy sociology' is a term used for analytical approaches to education policy (but also applicable to other public services) that conceives policy formation and institutionalisation as a process which connects the local enactment and experience of policy to wider ideological and socio-political influences over the shaping of institutions (Rivzi and Lingard, 2010). This approach focuses on the relationship between wider systematic global policy shifts and its practice, including the ways in which policy is mediated and mobilised within institutional contexts (Ball, 1997; 1999). In Ball's conceptualising, policy developments can take on almost paradigmatic ways of organising understanding of institutional practices, relations and subjectivities for whom they impact; be that students, educators and managers. Thus, whilst policy reform movements signal in part a reconfiguration of the aims and purposes of educational systems, they also embody re-workings of actors' lived experiences at an institutional level. Policy movements are also enshrined with values and discursive framings that shape key actors' thinking about institutions and how they should operate.

In adopting an analytical rather than normative approach to policy development, attention is shifted from a policy agenda's effective maintenance to the wider socio-political and institutional context through which it is mediated. In applying this approach to a policy agenda such as 'student engagement', closer analysis is given to the extent to which this reflects wider reform movements and other related policy movements within HE. A key concern within the policy sociology framework tradition is therefore critically engaging with the underlying assumption of a policy agenda in terms of what it seeks to achieve, what existent practices it may transform and what overall effects this may produce. Such an approach is captured neatly by Taylor et al., (1997) who discuss the analysis of policy as something which: 
... involves more than a narrow concern simply with a policy document or text. We need to understand the background and context of policies, including their historical antecedents and relations with other texts, and the short- and longer term impacts of policies in practice. A useful framework which encompasses this breadth distinguishes between contexts, texts and consequences of policy

(Taylor et al,. 1997, 44)

At one level, policy can be seen to reflect a wider political project of reform based on the reconfiguring of institutions and the nature of their activities. This is often predicated on a wider set of goals for institutions and how they should be organised to meet broader social and economic imperatives. At another level, generic reform agenda is accompanied by a set of discursive strategies that shapes ways of thinking consistent with reform goals (Fairclough, 2003). For instance, student-centred policy which emphasises 'learners at the heart of the system' employs a range of discursive techniques that foreground institutions' responsiveness in meeting students' demands, as well as students' active role in the service they experience (DBIS, 2011). However, as Ball (1999) argues, policy discourses on reform modernisation and enhancement can be paradoxical: students are sometimes enacted as 'active learners' and citizens whilst contemporaneously identified as being regulatory stakeholders and consumers. Similarly, senior managers can be depicted as 'change agents' as well as faithful implementers of reform (Wallace et al., 2011).

Generic policy goals are translated into institutional practices by a range of policy levers which help establish the pace and direction of reform. Within a market-driven HE context, there are some very immediate policy levers, the most significant being the transfer of costs onto 
individuals students, the large-scale production of institutional performance data via key metrics and the entry of new providers (Brown and Carasso, 2013). This in turn has generated a number of (largely unintended) consequences, including an increase in inter-institutional competition, reputational ranking and the widespread branding of institutions' offerings to an increasingly global audience. A further effect is the closer monitoring of the quality of teaching and learning, which in the UK is assessed through tools such as the National Student Survey which enables students to formally evaluate their experiences.

The three-fold policy theme model developed by Bell and Stevenson (2006) is potentially very useful in linking wider structural shifts to emergent policy agendas, including student engagement. These authors have identified three dominant policy frames - human capital, accountability and social justice - and are all applicable to policy developments in higher education, including student engagement. These themes all, to some degree, become organising principles in the way in which institutions seek to adapt to the changing social and politicoeconomic context in which they now exist.

In applying a policy sociology perspective to student engagement, a number of key areas of context need to be addressed. First are the wider macro-level political-economic drivers that shape this agenda and provide a framework for understanding current students' relationship to HE. The macro level provides a wider context to the policy and its interaction with national and global reform movements. Second is the meso-level, concerning the implementation, governance and evaluation of the policy at an institutional level. This includes policy instruments designed to best capture, enhance and evaluate how effectively students are engaged in their formal university experiences. Thirdly is the meaning and practice of student engagement at a micro level. This not only addresses the lived experience of this policy agenda, 
but also potentially different concepts of students' relationship to their institutions and the meanings ascribed to their formal experiences

\section{Macro level: the changing political economy of HE and related policy themes}

Several inter-weaving themes can be identified in terms of the broader macro-level framing to student engagement. First concerns the move towards increasing neoliberal governance in HE, manifest largely by the growing marketization of the system. This is closely allied to economically-driven logics pertaining to universities' role in responding to wider economic imperatives, not least in enhancing the future skills and human capital of the workforce. The neoliberalisation of $\mathrm{HE}$ systems is often intimately linked to increased performance management, informed largely by the principles of New Public Management and associated governance tools. Accordingly, it is seen that HE systems need to be more responsive to their external environment and accountable to diverse stakeholders' demands. Furthermore, any focus on macro-level shifts needs to consider the global massification of the system, encompassing a more heterogeneous student population and a more diverse range of institutional provisions.

The idea that higher education has been subject to the forces of neoliberal ideology and related policy technologies at a global level is now fairly well established and has been discussed extensively for several decades (Olssen and Peters, 2005; Ball, 2012; Lynch, 2014). One of the salient features of this movement has been the system-wide move towards marketization and the transformation of university outcomes, most particularly research and graduates, into marketable commodities which has purchase in a wider globalised milieu. The neoliberalisation of higher education and its accompanying marketization policy framework 
have been critically examined both for what it constitutes educationally and professionally, but also as genuine model of organisation and governance (Marginson, 2014).

The marketization of HE is most keenly felt in liberal economies such as the US, UK and Australia. Market-driven reform is characterised by a shift from providers to purchasers in controlling institutional-level delivery and related outcomes. This is seen to leverage quality of provision as fee-paying customers exert greater control over what they can expect higher education to provide and how well it meets their demands (Brown and Carasso, 2013). Providers are encouraged to compete on both quality and price, one seen as being a precedent to the other. These changes also impact on senior managers who ultimately have to implement policy makers' directives, mediate between central and local policy and broker the institutional acceptance for reform and its specific institutional adaptation (Wallace et al., 2011.

In a neoliberal policy environment, considerable focus is placed universities' outputs, not least the production of skilled and employable graduates. The logic of human capital theory (Becker, 1993) underscores considerable macro-level policy framings on the role and responsiveness of higher education institutions. First, HE is charged with supplying the economy with relevant skills and knowledge, mainly through the production of economically adept graduates who have engaged in relevant forms of learning. HEIs have become increasingly charged with developing and implementing modes of curricula and provision that best enhance the vocational competences and future employability of graduates (McCowan, 2016). This in turn is believed to enhance their so-called economic value when in the labour market. Human capital approaches see the continued expansion of HE as justified, based on the matched supply of graduates to their demand in the labour market and consequent enhancement of productivity. Given that HE is essentially an investment that accrues longer-term benefits, the shift of 
personal costs onto individuals is justified on the basis of a 'shared investment' between individuals, government and society.

One of the features of marketised HE is, however, the continued role of state regulation and audit which, in light of increased private costs, has intensified and strongly informed by the principles of New Public Management (Ferlie et al., 1996) Neoliberal policy frameworks effectively establish 'managed markets' (Palfreyman and Tapper, 2014), or what in the context of increased inter-institutional competition, might be seen as measured markets. In marketised HE systems, political and market accountability are often conjoined and interact reciprocally: the systematic regulation of intuitional performance through explicit forms of audit and evaluation are designed to enhance institutions' market positions, in turn driving demand. Institutional performance data provides key market information which purportedly informs student choice, potentially enabling institutions to increase their fee levels on the basis of relative performance on student-driven and student-evaluated output. In the UK following the introduction of a three-fold increase in student tuition fees there has been growing emphasis on higher education's role in providing a level of experience commensurate to students' personal financial contribution. The Browne review in the UK made explicit reference to the need for students to be sufficiently engaged given the personal costs involved (DBIS, 2011, 2-4).

HE systems have been increasingly subjected to a range of measures that have sought to regulate their performance against overarching national and international benchmarks, which includes students' and graduates' achievement of specified learning outcomes. The Bologna process in Europe, for instance, has resulted in greater cross-border convergence of a range of policies concerned with teaching, learning and assessment with related employability-focussed policy directives. Moreover, in many national contexts universities have been subject to 
international benchmarking in the form of international league tables and other markers of relative global standing (Locke, 2014).

Another macro-level influence is the global rise in mass higher education. This is also linked to a social justice policy theme as it concerns the inclusion of a more diverse student body receiving diverse modes of provision within various institutional contexts (Scott, 2009). Whilst mass HE has been in place for well over four decades, it has accelerated at a global level (Mok, 2016). Massification clearly produces assorted structural and internal effects upon HEIs: as more people enter them they need to adapt and grow new modes of provision to meet diverse stakeholder needs. One salient challenge for institutions is accommodating a changing student body, a large number of whom may not have entered in previous generations, including first generation 'non-traditional' students and those who have entered from less academic routes (Thomas and Quinn, 2007)

As a policy framework, massification is built on the wider goal of make HE more accessible to a wider and more diverse range of individuals. Whilst there is a clear economic imperative in terms of increasing the stock of human capital entering the economy, it has been couched in terms of social justice and inclusion. For instance, related 'widening participation' policy has sought to make HE more accessible by both reducing institutional barriers and encouraging participation amongst groups of potential students who perceive it beyond the realm of their aspiration. However, this is only one part of the inclusiveness agenda and once students enter they need to be encouraged to stay. The shift towards massified HE and the related growth in student diversity has informed practices that reflect this spirit, largely under the remit of more inclusive learning environments (Haggis, 2006). 
The macro-level context and its related structural shifts therefore provide a potentially significant contextual frame through which student engagement can be positioned within a changing HE environment. A number of salient features connect to a changing student experience and allied issues around students' levels of engagement. First, the preoccupation with human capital enhancement and the supply of appropriately skilled graduates resonates with the drive for more student-centred learning which provides pedagogically-relevant, skillscentred modes of curricula and assessment. Such provisions enable students to align their learning to future work-related activities and acquire so-called transferable skills that can enhance their economic scope and future employability. Conversely, passive learners might be construed as failing to acquire skills that enable them to proactively adapt to future economic demands.

Related to this is the notion of the active and purposive 'investment' students have made to their higher education in marketised, cost-driven HE. In seeking a return from providers purporting to enhance their future economic, student are encouraged to expect. In terms of accountability, the engaged student is one who not only has a greater stake in their institution and plays a proactive part in enhancing internal responsiveness so that this matches their expectations; s(he) is also someone who is sufficiently content with what their institutions provide and accordingly appraises this in a positive light. Lastly, in the quest for greater forms of inclusivity, enhanced student engagement is a means of connecting disparate groups of students (including 'non-traditional' learners) and acts as the antithesis to another experience which HEIs are clearly keen to abate: student alienation (Mann, 2001). The alienated student is not only someone who sits on the margins of HE, but is also disaffected with their experiences. This condition further entails significant institutional risks in terms of threatening student retention and satisfaction and is one which institutions are clearly keen to avoid. 
$\underline{\text { Meso level: institutional policy framework for enhancing student engagement }}$

In order to examine how macro-level contextual forces translate to the institutional level, further consideration is needed of the specific policy mechanism and governance approaches which ensure this agenda is actively pursued within HEIs. It has become recognised that quality assurance measures have increasingly factored the quality of student experience and learning into their criteria (Duzevic, 2015). Accordingly, quality assurance markers have moved beyond more distal resource-specific factors that may notionally enhance student experience - for instance, the physical environment, staff-student ratios, staff training and qualification - to ones which focus on how effectively students engage with their learning and appraise their institutions' provisions towards this end. As such, quality management systems have sought to align their measurements to how effectively they have engaged students, including the identification of good practices and ways of enhancing current provision (Nauffal, 2012).

There are clearly significant implications here in the ways students engage with HE and evaluate their formal experiences. Students now have considerably greater scope in regulating what and how institutions deliver: directly in terms of making formal evaluations of specific and wider institutional provisions; and indirectly through the choices they make, including which institutions and programme they attend. One of the main concerns at a governance level is ensuring that institutions are able to effectively embed provisions and 'best practice' strategies that fulfil the end goal of more effective teaching and learning. In the UK, this is formally regulated by the Quality Assurance Agency (QAA) through its periodic institutional reviews, and the criterion of student engagement has come to inform how institutions are appraised in this regard. In the words of QAA: 
Where student engagement is highly developed, pervading institution culture and clearly recognised by staff and student alike, these institutions tended to be those where related feature of good practice were found (QAA, 2014, 18)

The Quality Assurance Agency in the UK has, for instance, established seven indicators of 'sound practice' in relation to student engagement. Most, if not nearly all, of these make strong references to the institutional environment, taken to be conductive to the enrichment of student learning, including the 'cultures of continuous improvement' and collaborative dialogue between students and institutions. The latter relates to another salient feature of the governance of student engagement; namely student input and steerage towards enhancement. A key feature in all quality approaches to formally regulating student engagement is students' formal input, through a combination of measurements that purportedly capture their perceptions of institutional quality and effectiveness. This can take both the form of formal monitoring of quality via a range of local, national and cross-national evaluations, as well as dialogue and 'informed discussions' based on the sharing of information, partnership and student representation in institutional decision-making.

In the UK, the National Student Survey (NSS) is taken to be a significant lever in quality enhancement through the ways in which students appraise their university experience. But the measured market is not only captured by student evaluation: in some countries, including the UK, it is through the outcomes they achieve on graduation, namely their rates of employment. It is increasingly the case that students' future employment outcomes have become a key market signal, as well as an inferred marker of institutional quality and, indeed 'teaching quality' (Gibbs, 2016). The more recent development of the Teaching Excellence Framework 
in the UK following the 2016 White Paper signals an attempt to connect quality of provision with outcomes of formal student attainment, potentially resulting in the raising fee levels. Yet as Gibbs (2016) discusses, the extent to which outcome metrics, including graduate returns and retention rates, captures genuine process level quality is open to considerable question. Formal outcomes, as well as students' appraisal of institutional quality, are also determined by profile characteristics that may have little to do with actual learning experience.

At a pan-institutional level, a range of formal evaluative measures are used by institutions to capture how engaged students are, the areas where this is most manifest and the modes of institutional practice which might be enabling positive engagement. The most explicit student engagement measurement tool in relation to the formal measurement of student engagement is the National Survey of Student Engagement (NSSE), which was developed in the US but has since been applied in adapted in other countries, most notably Australia, New Zealand South Africa and is now also used in other continents, including the Middle East and China. A central feature of this instrument is the assessment of students' perceptions of what they have gained from their higher education and its relationship to the pedagogical and co-curricula activities provided by their institutions. It also encourages students' evaluations of their institutions' environmental conditions and their overall satisfaction with the quality of provision.

As a benchmarking tool, the NSSE in intended to enable institutions to review and plan for improved effectiveness, as well as provide comparative data against other institutions. The data provided from such surveys therefore potentially enables institutions to develop ways of enhancing institutional processes, organisation and pedagogic practices that provide a better student experience. Most significantly, the benchmarks are meant to be 'learner-centred' and to measure how, and in which main areas, students have invested in their learning. The NSSE 
has now extended to ten major categories, including active and collaborative learning, higherorder thinking, student-faculty interaction and the supportiveness of the learning environment.

Proponents of NSSE view it as providing comprehensive data on students' perceptions of how effectively different facets of their learning experiences are being met. A key issue, and one which has not received extensive critical attention, is how accurate and informative its measurements are in capturing the quality of learning beyond codified and quantifiable markers, as well as how effectively it leverages institutional enhancement. A number of researchers such as Buckley (2014) and Portes (2011) have argued that instruments like the NSSE measure student engagement only by proxy to any direct and genuine measure of student development. An obvious line of criticism is that students' independent learning, including how effectively or 'deeply' they have learned and engaged with their disciplines, may not be adequately captured by such surveys. This also relates to continued concerns over the potential conflation of 'satisfaction' with learning experiences that do not necessarily provide genuine quality, rigour and learning gains.

In the UK, the current National Student Survey is being adapted to shift its orientation from more general and contentious items around how satisfied students are with provision to more detailed assessment of student perception of how any perceived gains might be attributable to their learning environment. Whilst the National Student Survey in the UK remains divisive, it carries significant traction in the ways UK institutions manage information about the quality of their provision. In the current market-driven environment, this is now a key element of the 'key information sets' which students are encouraged to consult in making informed decisions about where to study. Irrespective of any debate over how valid this tool is and how well it 
captures student engagement or quality of learning, it has become a powerful symbol in institutions' public claims of what they can offer students.

An underlying concern with student involvement in quality enhancement is to include students at all levels of formal governance. At an institutional level, this can take the form of student involvement in strategic planning around curricula, teaching and learning and student support. Students' unions clearly have a potentially significant leveraging role here in mediating the link between the bottom-up quality concerns of the student body and senior managers' strategic decisions.

The governance of student engagement has been shown to be mediated by organisational culture and context, which includes how senior management approach teaching and learning enhancement (van der Velden, 2012). This can reflect the actual behaviours of senior managers and how direct a role they play (e.g. attending curricula meetings, student union boards etc), but also how much student engagement is part of an institutions' strategic direction. Van der Velden's research revealed discernible institutional variations in the ways in which student engagement is organisationally mediated. For instance, in bureaucratically-modelled institutions, the strategic direction of student engagement enhancement was mainly technocratic and information-driven and largely externally-compliant. More collegial cultures, on the other hand, were shown to promote an approach based on more partnership and consultative-oriented approach to the management of the student experience, including much more interaction between students and institutional managers at all levels. 
Micro context and changing student-institutional relations: engaging a student-consumer or $\underline{\text { self-directed learner? }}$

The last level of context through which the student engagement policy agenda is mediated is at a micro level and concerns the ways in which student engagement policy translates to students' immediate pedagogical experiences. This context is clearly important as it brings into focus students' relationships with their institutions in light of the changing policy context. The macro and meso level, in particular policy levers linked to marketization and performance management, feed into the micro context as they as they provide students with a wider frame of reference around how they approach HE and what they can expect.

The first issue concerns the way in ways in which engagement practices are enacted at a pedagogic level and the various teaching and learning strategies that seek to enhance the quality of students' formal learning. Much of the student engagement literature has often presented student engagement pedagogy and curricula in an ostensibly positive light, pointing towards a range of associated benefits to pedagogic practices that have explicitly sought to enhance engagement. This includes benefits such as improved grades, higher class retention, improved class evaluation and measures of academic development. The methodologies and the practices they seek to illuminate vary, but overall a typical emerges: teachers seek to implement engagement practices based on concerns with student performance, attendance or retention; a new teaching innovation which has an engagement approach is introduced over a specified time period; students' performance (either within or between students) is then compared against the status quo, non-engagement-friendly practice (see Evans et al., 2016). 
Much of the pedagogical literature therefore emphasises the efficacy of various practices associated with more engaged forms of student learning together with positive impacts on learning outcomes, whether cognitively, affectively or dispositionally. This has often positioned student engagement practices as predominately 'student-centred' which enhances learning experiences (Frambach et al., 2014). The range of pedagogic approaches, sometimes termed 'high impact', for student engagement has been discussed elsewhere (see Kuh, 2010 and Evans et al., 2016) and is beyond the scope and focus of this paper. However, a number of common and overlapping themes emerge and connect to what is often conceived in terms of experiential, social constructivist modes of learning. One of these is the promotion of students' active participation and greater contributory role in curricula and pedagogy; largely mediated through more problem-based, professional-facing, or 'applied' learning. Another is the development of student agency and extensions of their learning capacity, often referred to as 'self-regulated' learning (Zimmerman, 1989). Self-regulated learning entails students being able to take active ownership of their learning in ways which allow them to make active decisions and, in turn, generate desirable future learning opportunities and outcomes.

Another theme which has generated discussion is the extent to which students can be viewed as 'partners' or indeed 'producers'/'co-producers' within HEIs (Neary, 2009). This emphasises students' roles as active participants rather than passive knowledge recipients. Thus, aside from being an antidote to largely passive and inactive modes of student learning, this conception implies that higher education involves a reciprocal exchange between students and their institutions. The idea of 'co-producing' learning outcomes is seen to accentuate the potentially complementary nature of students' involvement in their programmes. Accordingly, effort towards fulfilling educational goals is a joint endeavour entailing mutual input between different parties - students, teachers and HE managers. 
More critical literatures have emerged in recent times that provide a counter-view that all engagement practices are inherently beneficial and that students are not necessarily immune to the effects of the changing context of higher education. The first issue addresses some critical questions about the ways in contemporary students' relations to their institutions is mediated by the changing policy context, in particular least market-driven policy. There has been continued debate over the extent to which students have become positioned as 'consumers', particularly in market-driven HE systems, where the costs of studying have shifted onto individuals and they have supposedly greater scope to choose which services to purchase (Brown and Carasso, 2013; Molesworth et al., 2010). Whilst this may have become an increasing reality and internalised by a growing body of students, its scale is still questionable. In all cases, the wider economic framing of the value to studying in HE appears to be shaping expectations concerning institutions' effectiveness in meeting their needs, together with the sense that they have stronger regulatory power to shape practices and an awareness of their rights under consumer law (DBIS, 2016).

There are clearly pedagogic implications here for the ways which speak strongly to student engagement. There is emerging evidence that students who have adopted a more consumerorientated approach are likely to achieve less academically (Bunce et al., 2016). The corollaries of consumerist orientations include the tendency towards extrinsic rather than intrinsic learning approaches, the minimisation of effort and the attribution of academic difficulty on variable provision rather than personal proactivity. The Bunce et al., research has shown how consumerist orientations are likely to entail challenges for student engagement and what HE teachers must to do negotiate such approaches. At its extreme, students may seek instant gratification and eagerness to receive more accessible modes of pedagogic engagement that 
fulfils short-term goals: often the attainment of desired outcomes. More commonly, students may equate, often through some degree of calculation, the value of their learning against its costs and whether it has resulted in so-called 'value for money'. Experiences which have not 'engaged' may be discounted as irrelevant, or of limited immediate short-term outcome, although this may not necessarily be a result of 'faulty provision' as such but instead undesired cognitive expenditure or lack of interest

The second critical thread on the student engagement agenda, at a micro level, questions the extent to which this is a panacea to enhancing the student learning experience and provides students with the requisite tools for self-motivation and empowerment. One particular issue concerns overt and behavioural modes of student participation and the level to which practices designed to 'involve' students actually have that desired effect. Macfarlane $(2013 ; 2015)$ has made a number of critical observations on student engagement, highlighting the various problems associated with student engagement practices which may claim to have universal student value and impact. One of these is the move towards mandatory participation in learning, reflected in engagement measures such as class attendance, active class contribution and group interactions. Whilst this may be conducive for some students, it is questionable how beneficial this is for all students and may conversely alienate, or indeed vilify, students who prefer more solitary or independent learning. Relatedly, equating positive and meaningful learning to largely behavioural measures as in the above may not actually capture the quality of learning, including the extent to which genuine knowledge and understanding has been developed. As Macfarlane critically observes, student engagement risks becoming a largely performative practice whereby the manifestations of students' active participation - embodied, emotional and verbal - become over-arching criteria upon which to judge whether a practice is effective. 
The issue of student performativity thus opens up a significant set of issues around the micro context of the formal environment and how effectively this mediates student learning experiences. Whilst there may appear to be a positive alignment between class practice and student learning, elements of participative compliance potentially subvert the kinds of studentcentred, constructivist-orientated activities which are claimed to be integral to student engagement. Furthermore, it might be argued that in the drive to elicit positive and measurable student outcomes - immediate satisfaction, improved academic performance, good grades and higher retention rates- the converse may be occurring. Performativity also relates to an increasing instrumentality in terms of aligning learning to future economic outcomes and finding stronger vocational synergies between academic learning and future employment - or, more narrowly, graduates' 'employability'.

Discussion: student engagement: a student-centred or performative concept?

This article has located the student engagement policy agenda in a wider context and examined the various levels of analysis through which this policy agenda is articulated and understood. Managing student experience and attendant expectations around institutions' offerings and provisions now clearly represents a major issue at a strategic leadership level, although institutions respond to this in different ways. The effective management of student engagement is clearly seen to have a bearing upon how, and to what effect, students formally engage with higher education.

This article has firstly explored the wider why issues of student engagement in terms of the macro-level framing of reform movements in $\mathrm{HE}$ and their political and economic antecedents. Not engaging at this level means that there is limited context to the what and how policy 
questions concerning the institutionalisation and enactment of student engagement at the level of provision, practice and lived experience. Thus, the article has sought to explore the wider economic and structural antecedents to this policy agenda, how this is mediated through institutions' policy approaches and its potentially contested meanings at the level of student experience. This approach in part connects to other critical literature on student engagement (Zepke, 2015; Bundel and Corbin, 2012) as it has aimed to locate it in wider reform and associated ideological framings. The claim that student engagement is directly aligned to neoliberal governance, what Zepke terms an 'elective affinity', implies a symbiotic interplay between wider politico-economic forces and institutional-level practices. The influence of this policy context and its related policy drivers, in particular the measured performance of institutions' throughputs and outputs, is clearly not remote. The policy agenda has come to be associated with new forms of performance management and codified sets of practice and measurements in HEIs that are linked to desired forms of learning outcomes amongst the student body.

This analysis has been informed mainly by a policy sociology approach. In adopting this approach, it has been argued that student engagement has taken on a paradigmatic nature in terms of organising understanding of higher education learning and of students' relationship to their institutions. This paradigm is also mediated at a wider cultural and politico-economic level and maps onto fundamental issues about changing structures, governance of HE systems and their relationship to economy. The sociology of educational transformation, encompassing reform movements and connected policy frameworks and levers, is captured effectively in Bernstein's (1996) concept of classification and framing. This concept particularly helps explain the ways in which educational experiences are, to some degree, a by-product of the way in which educational institutions are positioned more widely within economic systems' 
modes of operation. His work on pedagogic identity illustrates how the core elements that constitute university education, including the status of knowledge, curriculum and rules of academic engagement and learning, are largely constitutive of wider economic framing. Learners' and educators' identities in higher education are not only fashioned by the specific framing of their subject disciplines and overall pedagogic goals, but also by shifting classifications of what a student learning experience should look like and constitute:

'This weakening of stable, unambiguous, collective resources for the construction of identities, consequent upon this new period of transitional capitalism, has brought about a disturbance and disembedding of identities and so created the possibility of new identity constructions' (Bernstein, 1996, 76)

This is particularly apposite for the discussion of student engagement in a mass marketised context. The so-called 'disembedding' process that Bernstein discusses is both a consequence of the new institutional forms of higher education, as well as the deeper structural and sociopolitical shifts in the economy. These of course do not operate as abstract externalities to higher education institutions: their influence is channelled and mediated by policies enacted within institutions, which in turn shape the direction and scale of reform agendas. These further penetrate the identities of student and teachers and how they perceive their role within institutions, also enabling institutional actors to assume new mediatory (and regulatory) roles in shaping institutional response to policy.

At the level of institutional practice there are clearly important implications for students' relationship with their institutions at a time when this has been given closer attention. At a governance level, student input in the regulation of effective student engagement may have 
multiple purposes: it not only potentially enables enrichment of practice, but has an engagement function in its own right if students move closer to the core of decision-making and strategic direction. The positioning of students as 'change agents', or at least political agents who can exercise democratic accountability through purposive dialogue and exchange, signals an extension of students' agency (Klemenčič, 2014). This can be achieved in ways that are not solely attributable to formal teaching and learning experiences. This also appeals to notions of 'co-production', often seen to be the antithesis of a passive consumer approach (Neary, 2009). Therefore, if HE is conceived more widely as a 'complementary good' whereby students are both recipients and co-producers of higher education, then relationships are not exclusively reducible to what they receive, but also input to the process.

However, it is in the interplay between student engagement and student performance where questions remain over how genuinely student-centred this policy agenda is, particularly when associated with largely behavioural and specious measurements of student outcome. Whilst student engagement is often read as a proactive, student-centred agenda, it might also be read as a performative mode of practice that not only links to students' changing role and position as regulators of $\mathrm{HE}$ - at its 'heart' - but also as the ways in which institutions seek to manage this changing dynamic. Performativity has been conceived in terms of students' embodied performance and participation in formal settings, but it is also concerned with measurable outcomes and performance and their public showcasing. In this regard, there is clearly much at stake for students and institutions in the changing policy environment. 


\section{$\underline{\text { References }}$}

Ball. S. (1997) 'Policy sociology and critical policy research: a personal review of recent education policy and policy research', British Educational Research Journal 23 (3): 257-274.

Ball, S. (1999) 'Labour, learning and the economy: a policy sociology approach, Cambridge Journal of Education 29 (2): 196-206.

Ball, S. (2012) 'Performativity, commodification and commitment: an I-spy guide to the neoliberal university', British Journal of Educational Studies 60(1): 17-28.

Baron, P. \& Corbin, L. (2012) 'Student Engagement: rhetoric and reality', Higher Education Research and Development 31(6): 759-772.

Bell, L. and Stevenson, H. (2006) Education Policy: process, themes and impact, London: Routledge.

Becker, G.S. (1993) Human Capital: theoretical and empirical analysis with special reference to education ( $3^{\text {rd }}$ Edition).Chicago: University of Chicago Press.

Bernstein B. (1996) Pedagogy, Symbolic Control and Identity: theory, research, critique, London: Taylor and Francis.

Brown, R. and Carasso, H. (2013) Everything for sale: the marketisation of UK higher education, London: Routledge, 
Buckley, A. (2014) 'How radical is student engagement? (and what is it for?)', Student Engagement and Experience Journal 3(2): 1-23.

Bunce, L. Baird, A. \& Jones, S (2016) 'The student-as-consumer approach in higher education and its effect on academic performance', Studies in Higher Education (forthcoming)

Coates, H. (2005) 'The value of student engagement for higher education quality Assurance. Quality in Higher Education' 11 (1): 25-36.

Department for Business, Innovation and Skills (2011) Higher Education: students are the heart of the system, London: HMSO.

Department for Business, Innovation and Skills (2016) Success as a Knowledge Economy, London: HMSO

Duzevic, I. (2015) 'A conceptual framework for analysing the impact of influences on student engagement and learning', Tertiary Education and Management 21 (1): 66-79.

Evans, C., Muijs, D. \& Tomlinson, M. (2016) Engaged Student Learning: high impact pedagogies to enhance student engagement, York: Higher Education Academy

Fairclough, N. (2013) Critical Discourse Analysis: the critical study of language, London: Routledge 
Ferlie, E., Ashburner, L., Fitzgerald, L. and Pettigrew, A. (1996) The New Public Management in Action, Oxford: Oxford University Press.

Frambach, J.M., Driessen, E.W., Beh, P., van der Vleuten, C.P.M. (2013) 'Quiet or questioning? Students' discussion behaviors in student-centered education across cultures', Studies in Higher Education, 39 (6): 1001- 1021.

Gibbs, G. (2016) Response to the Green Paper - teaching, London: Higher Education Policy Institute.

Haggis, T. (2006) 'Pedagogies for diversity: retaining critical challenge amidst concerns of ‘dumbing down', Studies in Higher Education 31(5): 521-535.

Klemenčič, M. (2014) 'Student power in a global perspective and contemporary trends in student organising', Studies in Higher Education 39 (3): 396-411.

Kuh, G.D. (2010) High- Impact Educational Practices: What They Are, Who Has Access To Them and Why They Matter. American Association for Colleges and Universities.

Locke, W. (2014) 'The intensification of rankings in an increasingly marketised higher education environment', European Journal of Education 49 (1): 77-90.

Lynch, K. (2014) 'New Managerialism, Neoliberalism and ranking', Ethics in Science and Environmental Politics 13(2): 141-153. 
Macfarlane, B. (2015) 'Student performativity in higher education: converting learning as a private space into a public performance', Higher Education Research and Development 34(2): $338-350$.

Macfarlane, B. (2013) 'The surveillance of learning: a critical analysis of university attendance', Higher Education Quarterly 67(4): 386-373.

Mann, S. (2001) 'Alternative perspectives on the student experience: student alienation', Studies in Higher Education 26(1): 7-19.

Marginson, S. (2014) 'The impossibility of capitalist markets in higher education', Journal of Education Policy 28 (3): 553-570.

McCowan, T. (2016) 'Should Universities Promote Employability?, Theory and Research in Education', (Doi:10.1177/1477878515598060)

Mok, K. H. (2016) 'Critical reflections on the massification of higher education, graduate employment and social mobility', Journal of Education and Work 29 (1): 1-13.

Molesworth, M., Scullion, R. \& Nixon, E. (Eds) (2010) The Marketisation of Higher Education and the Student a Consumer, London: Routledge.

Nauffal, D. (2012) 'Assessment of Student Engagement: an analysis of trends', Tertiary Education and Management 18 (2): 171-191. 
Neary, M. (2009) 'Student as producer: Risk, responsibility and rich learning environments in higher education'. In: Barlow, J., Louw, G. and Price, M. (eds.) Social Purpose and Creativity - integrating learning in the real-world, Brighton: Brighton University Press.

Olssen, M. \& Peters, M. (2005) 'Neoliberalism, higher education and the knowledge economy', Journal of Education Policy 20 (3): 313-345.

Palfreyman, D. \& Tapper, T. (2014) Reshaping the University: the rise of the regulated market in higher education, Oxford: Oxford University Press.

Porter, S. (2011) 'Do college surveys have any validity?' Higher Education Review 35 (1): 4576.

Quality Assurance Agency for Higher Education (2014) Exploring themes to improve quality for students, Gloucester: QAA

Rizvi, F. and Lingard, B. (2010) Globalizing Education Policy. London: Routledge.

Scott, P. (2009) 'Structural changes in higher education: the case of the United Kingdom', in D. Palfreyman and T. Taper (Eds) Structuring Mass Higher Education: the role of elite institutions. London: Routledge.

Taylor, S., Rizvi, F., Lingard, B.\& Henry, M. (1997) Educational Policy and the Politics of Change, London: Routledge 
Thomas, L. \& Quinn, J. (2007) First Generation Entry in Higher Education, Buckingham: Open University Press.

Trowler, V. (2010). Student engagement: literature review. York: HEA

van der Velden, G. (2012) 'Institutional Level Student Engagement and Organisational Cultures', Higher Education Quarterly 66 (3): 227-247.

Wallace, M., Deem, R., O’Reilly, D., \& Tomlinson, M. (2011) 'Developing Leadership Capacity in English Secondary Schools and Universities: global positioning and local mediation, British Journal of Educational Studies 59, (1): 21-40.

Zepke, N. (2015) 'What future for student engagement in neoliberal times?, Higher Education 69 (4): 694-704.

Zimmerman B. J. (1989). 'A social cognitive view of self-regulated academic learning'. Journal of Educational Psychology 81: 329-339 